\title{
Perder um filho em idade pediátrica: estudo qualitativo do apoio ao luto parental
}

Ana Rita Costaํㅜ, Filipe Almeida²

\section{RESUMO}

Objetivos: A perda de um filho em idade pediátrica é uma das vivências mais dolorosas que o ser humano pode enfrentar, sendo que o luto parental é um processo intenso e dinâmico que urge acompanhar e apoiar. Assim, pretende-se identificar necessidades a suprir no apoio prestado pelos profissionais de saúde e pela entidade Centro Hospitalar Universitário de São João (CHUSJ) a pais que vivenciaram a morte de um filho em idade pediátrica por doença oncológica e delinear recomendações para a melhoria desse apoio.

Métodos: Estudo qualitativo baseado em entrevistas semiestruturadas a pais que perderam um filho em idade pediátrica por doença oncológica, acompanhados no Serviço de Oncologia Pediátrica (SOP) do CHUSJ. Após transcrição das entrevistas procedeu-se à análise qualitativa dos dados com recurso ao software ATLAS.ti.

Resultados: Os dados colhidos confirmam o impacto que a doença oncológica e a perda de um filho têm na vida de um pai a nível pessoal, familiar, social e profissional. Identificaram-se pontos fortes nos apoios prestados a nível emocional, instrumental e informacional, principalmente ao longo do período de doença e fim de vida (luto antecipatório). Os principais aspetos a melhorar pela entidade hospitalar e pela equipa de profissionais de saúde relacionam-se com a comunicação de más notícias, articulação com outras unidades de saúde (e.g., cuidados de saúde primários) ou de ação social e prestação de apoio psicológico. Destaca-se a necessidade de reforçar o apoio ao luto após a morte do filho.

Conclusão: À semelhança do realizado em vários países, é pertinente investir nos cuidados paliativos pediátricos e na estruturação de programas formais de apoio ao luto parental. Neste sentido, considera-se importante estudar mais aprofundadamente esta realidade a nível nacional, para melhor definir os pontos a reforçar no apoio prestado a quem perde um filho.

Palavras-chave: Oncologia pediátrica; Luto; Apoio; Parentalidade.

\section{INTRODUÇÃO}

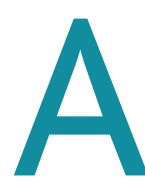

Vida pressupõe a inevitabilidade da Morte. Porém, não é hoje expectável que esta vida tenha um fim prematuro, principalmente em idade pediátrica, dada a tendência global de diminuição da mortalidade nesta faixa etária. Portugal ocupa, inclusive, um lugar de destaque no panorama mundial, nomeadamente pela diminuição da taxa de mortalidade infantil, com uma redução superior a $90 \%$ em quatro décadas. ${ }^{1}$ Além disso, sob as condicionantes profissionais e financeiras das sociedades desenvolvidas, os filhos são fruto de decisões ponderadas - um

1. Faculdade de Medicina, Universidade do Porto. Porto, Portugal. 2. Médico Pediatra. Diretor do Serviço de Humanização, Centro Hospitalar Universitário de São João. Porto, Portugal. «bem» precioso - e a sua perda é ininteligível, contranatura e avassaladora, modificando profundamente a estrutura e a dinâmica familiares. ${ }^{2-3}$

Se a morte de um cônjuge simboliza a perda de um parceiro de vida, a morte de um filho simboliza o desmoronar de um projeto de vida. É, assim, a experiência mais difícil, intensa, traumática e duradoura da vida de um pai, ${ }^{4-6}$ com marcados impactos diretos na sua saúde física e psicológica. ${ }^{7}$

\section{Luto parental}

O processo de luto subjacente à perda de um filho é um mecanismo natural e necessário para que os pais possam retomar a sua vida ativa, adaptando-se a uma nova realidade. ${ }^{8}$ De facto, não se trata de um regresso à vida dita normal. Após a morte do filho, os pais adotam 
uma nova forma de ser e estar na vida. É um caminhar, aparentemente sem fim à vista, que visa a recuperação, preservando a parentalidade na ausência física do filho e experienciando um sofrimento profundo com vista a um «renascimento» do Eu. ${ }^{6}$ É certo que quem perde alguém nunca mais é o mesmo ${ }^{9}$ como se de uma cicatriz se tratasse; não sangra, mas fica uma marca permanente.

Percorrer as fases do luto não é algo linear; qualquer luto saudável se faz de avanços e retrocessos. ${ }^{10}$ Cada percurso é sempre verdadeiramente individual, atento aos modelos culturais pessoais e às experiências de vida. Porém, sendo especialmente traumática, a perda de um filho acarreta per se um risco aumentado de luto complicado, ${ }^{11}$ ou seja, de uma inadequada adaptação à nova realidade, com repercussões marcadas na qualidade de vida. ${ }^{12-13}$ Além do impacto na saúde física (risco aumentado de desenvolver/agravar comorbilidades), perder um filho é um fator de distress que propicia psicopatologia, podendo originar depressão ou sintomatologia pós-traumática persistente e, no limite, levar ao suicídio. ${ }^{8,14}$ Fatores situacionais (gestão da doença, vivência da fase de fim de vida ou circunstâncias da morte), interpessoais (apoio de familiares e amigos) e intrapessoais (recursos e estratégias de cada um para lidar com a perda) influenciam o processo de luto. ${ }^{2,7}$ Justifica-se, pois, a necessidade de investir no acompanhamento e apoio adequados.

\section{Morte por doença oncológica}

Reconhece-se o peso que o diagnóstico de cancro tem na sociedade: associado a internamentos regulares, intervenções médicas dolorosas e efeitos adversos impactantes, é, para alguns, sinónimo de morte antecipada. ${ }^{15}$ De facto, a doença oncológica continua a ser uma das principais causas de mortalidade pediátrica em todo o mundo, ${ }^{16}$ apesar de apresentar elevadas taxas de sobrevivência nos países de alto rendimento. ${ }^{17}$

Um pai, perante este diagnóstico ameaçador da vida do filho, sofre inevitavelmente repercussões no seu bem-estar. À crise psicológica quase imediata, marcada por ansiedade e sintomas dissociativos, ${ }^{18}$ juntam-se progressivamente novos desafios inerentes à cronicidade da doença oncológica. O funcionamento familiar, a relação conjugal, a vida em sociedade e a estabilidade financeira são ameaçados, ${ }^{3}$ contribuindo para um estado de stress crónico nos progenitores, que sentem pouco controlo sobre os acontecimentos. ${ }^{18}$

De facto, a criança ou jovem com cancro e a sua família vivenciam uma sucessão de perdas. Perde-se a saúde, a estrutura familiar estabelecida, $o$ aconchego do domicílio, as rotinas, o cabelo. Perdem-se as capacidades (a marcha, a deglutição, a visão...), a autonomia, a esperança. Cada perda implica uma adaptação e, portanto, antes do luto pela morte do filho, os pais experienciam um luto antecipatório, em que tentam processar a perda iminente..$^{19}$

É, portanto, impreterível estar atento às necessidades dos pais, desde o início e ao longo de todas as etapas do processo, para que possamos atuar atempadamente e prestar apoio adequado, fortalecendo-os no seu papel de cuidadores de um filho doente.

\section{Apoio ao luto parental}

Existem na literatura estudos que concluem que pais que perderam filhos valorizam apoio em três domínios: emocional, instrumental e informacional..$^{20-23}$

Define-se apoio emocional como o conjunto de comportamentos que permitem estabelecer relações de empatia, propiciando que o recetor se sinta cuidado, estimado e valorizado. ${ }^{23}$ Este apoio pode ser prestado por familiares e amigos, mas também por profissionais de saúde, entre outros. ${ }^{21}$

$\mathrm{O}$ apoio instrumental baseia-se principalmente em ajudas práticas e tangíveis, com impacto direto nos progenitores. É, geralmente, prestado pela família e por profissionais de saúde dos cuidados primários e secundários. Qualquer comportamento que vise facilitar a gestão do processo pode incluir-se nesta categoria. ${ }^{21}$

$\mathrm{O}$ apoio informacional - normalmente da competência dos profissionais de saúde responsáveis pelo acompanhamento clínico a nível hospitalar - relaciona-se com a partilha de informação e/ou conselhos que orientem os pais, promovam a sua confiança e os capacitem para as tomadas de decisão. ${ }^{21}$

Percebendo a importância de gerir adequadamente o luto, vários países têm vindo a criar programas formais de acompanhamento às famílias que vivenciam esta situação. Estes incluem geralmente psicoterapia, grupos de entreajuda, partilha de literatura relevante, telefonemas e envio de postais por equipas hospitalares multidisciplinares, entre outras medidas. ${ }^{4,24-26}$ 
Também se tem apostado nos cuidados paliativos pediátricos (CPP), cuja missão é prestar cuidados holísticos à criança ou jovem com doença ameaçadora de vida, incluindo apoio à família. Estes cuidados podem iniciar-se aquando do diagnóstico e estender-se para lá da morte. ${ }^{5,27-28}$ Numa Europa em que alguns países conseguem já uma verdadeira integração dos CPP no sistema de saúde (nível 5), Portugal tem-se destacado positivamente pela evolução nos últimos anos, apresentando atualmente provisão generalizada de CPP com planos para desenvolvimento e futura integração (nível 4). ${ }^{29-31}$

Porém, a morte de um filho em idade pediátrica é ainda pouco estudada a nível nacional e a dificuldade em falar abertamente sobre o tema relega para segundo plano uma das experiências mais complexas da vida humana. ${ }^{6}$ É, pois, perentório orientar esforços para a investigação nesta área, que incontestavelmente põe à prova a essência do ser humano e obriga a uma medicina humanizada.

O Centro Hospitalar Universitário de São João (CHUSJ) tem investido precisamente na Humanização da Medicina. Este trabalho propõe-se complementar esses esforços, através da identificação de necessidades a suprir no apoio prestado pelos profissionais de saúde e pela entidade hospitalar a pais que vivenciaram a morte de um filho em idade pediátrica por doença oncológica. Adicionalmente, propõe-se delinear recomendações para melhoria desse apoio.

\section{MÉTODOS}

\section{Desenho do estudo}

A metodologia qualitativa utilizada - grounded theo$r y$ - visa compreender experiências complexas, na perspetiva e no contexto de quem as vivenciou..$^{32-34}$ Para tal, recolheram-se testemunhos de pais que perderam filhos em idade pediátrica por doença oncológica, através de entrevistas presenciais semiestruturadas. Pela sensibilidade requerida na condução das mesmas, estabeleceuse que seriam moderadas pela investigadora principal e pelo coinvestigador (especialista em pediatria e com subespecialidade em cuidados intensivos pediátricos).

\section{Amostra}

Aprovado o protocolo pela Comissão de Ética (CE) do CHUSJ, o profissional de ligação* do Serviço de Oncologia Pediátrica (SOP) selecionou os participantes, se- gundo um processo de amostragem por conveniência, com os seguintes critérios de inclusão: pai e/ou mãe em luto pela morte de um filho em idade pediátrica com doença oncológica, acompanhamento clínico no SOP do CHUSJ e falecimento do filho nos últimos 10 anos. A recusa em participar ou a impossibilidade de agendamento de entrevista constituíram critérios de exclusão.

O recrutamento iniciou-se com o contacto telefónico pelo profissional de ligação, que apresentou sumariamente o projeto, auscultou o interesse em participar e enviou, por carta, o documento "Informação ao Participante" a oito selecionados. A investigadora principal estabeleceu novo contacto telefónico para marcação das entrevistas: dos oito contactados, cinco marcaram e confirmaram a entrevista $(62,5 \%)$. Os restantes foram excluídos por recusa, incompatibilidade de disponibilidades ou não confirmação da marcação. Uma entrevista contou com a intervenção de ambos os progenitores, prosseguindo o projeto com seis participantes.

\section{Recolha de dados}

No início de cada entrevista garantiu-se a confidencialidade e o anonimato das informações, solicitando-se autorização para gravação áudio (a destruir após transcrição). Procedeu-se à caracterização demográfica dos participantes e do filho falecido.

Aplicou-se o Índice de Bem-Estar Pessoal (IBP), validado para a população portuguesa, visando medir o bem-estar subjetivo dos participantes. Este analisa oito domínios de «Satisfação com a vida em geral», pontuados de 0 (totalmente insatisfeito) a 10 (totalmente satisfeito). Somando o total de pontos e convertendo-o na percentagem em relação à pontuação máxima da escala (\%SM) calculou-se o bem-estar subjetivo dos participantes. $^{35}$

Pelo caráter flexível das entrevistas semiestruturadas, e apesar dos investigadores terem delineado tópicos orientadores, as perguntas colocadas variaram consoante os pontos abordados por cada participante. ${ }^{36}$

\section{Análise}

A investigadora principal transcreveu verbatim a gravação de cada entrevista e procedeu a uma primeira

*Profissional do serviço requerido pela CE para fazer o primeiro contacto com os putativos participantes. 
leitura para compreensão global da experiência de cada participante. Numa segunda leitura explorou o conteúdo linha-a-linha, codificou tópicos emergentes com o auxílio do software ATLAS.ti e inferiu os temas gerais. Posteriormente, explorou a existência de padrões entre os vários tópicos e temas.

\section{RESULTADOS}

Para garantir o anonimato dos testemunhos partilhados nos resultados, simbolizam-se as mães entrevistadas por Mx e os pais por Px (sendo x o número atribuído à entrevista). Os filhos falecidos são simbolizados por F, os filhos vivos por Ff e o médico assistente por MA.

\section{Entrevistas}

Os investigadores realizaram cinco entrevistas (duas no CHUSJ, duas no domicílio, uma numa pastelaria) a um total de seis participantes, entre 4 de janeiro e $7 \mathrm{de}$ março de 2020, com duração entre 43 minutos e 1 hora e 28 minutos.

\section{Participantes}

Os participantes e seus filhos falecidos são caracterizados nas Tabelas 1 e 2. A mediana de idades dos participantes é de 37,5 anos com amplitude interquartil de seis anos. Todos os agregados familiares têm um filho vivo (apenas um nasceu após o falecimento do irmão). Os filhos doentes faleceram entre 2015 e 2019: três na faixa dos 2-5 anos, um na dos 6-10 anos e um com $>12$ anos. O acompanhamento pelo SOP do CHUSJ variou entre oito e 66 meses. Em três casos $(60 \%)$ registou-se uma admissão temporária para tratamento no Instituto Português de Oncologia do Porto Francisco Gentil (IPO-Porto).

\section{Índice de Bem-Estar Pessoal}

A aplicação do IBP permitiu calcular o bem-estar subjetivo (BES) atual de cada participante (Tabela 3). O valor médio de 75,0\%SM (mínimo 50,0\%SM e máximo $92,5 \% \mathrm{SM}$ ) indicia que, no geral, os participantes estão satisfeitos com a sua vida atual. Em média, consideraram como mais satisfatório o sentimento de segurança $(8,0)$ e menos satisfatório o domínio da realização pessoal $(6,8)$. O item da espiritualidade/religião recebeu a pior avaliação (M5 avaliou com 2). Coincide que o

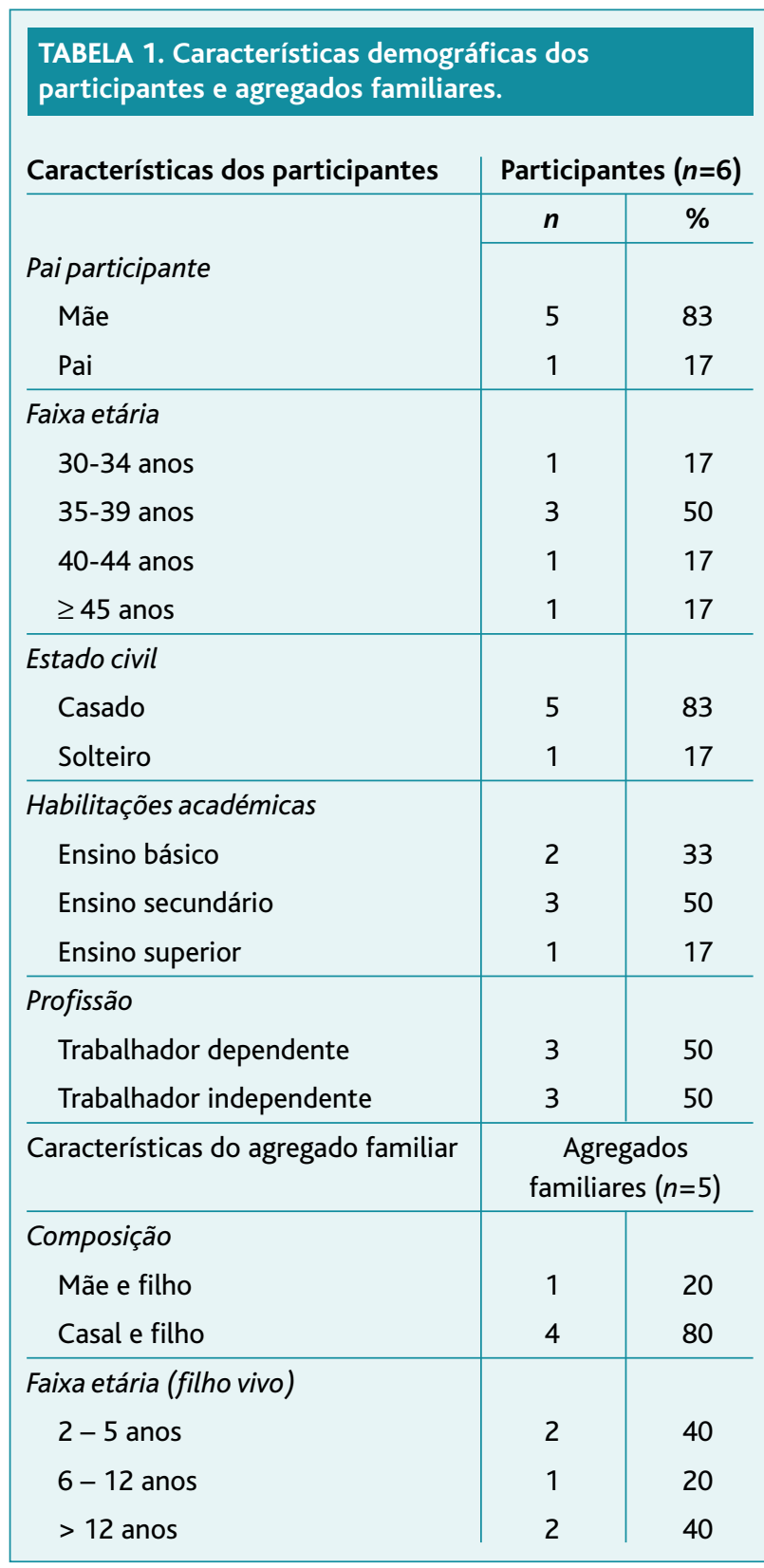

participante com pontuação mais elevada é aquele cujo filho faleceu há mais tempo e o que pontuou menos vivenciou a perda mais recente.

\section{A. Impacto \\ Impacto da doença e morte do filho}

Cada participante descreveu o impacto sentido nas várias esferas da sua vida - pessoal, familiar, social e 


\begin{tabular}{|c|c|c|}
\hline Características dos filhos falecidos & \multicolumn{2}{|c|}{ Filhos $(n=5)$} \\
\hline \multirow[b]{2}{*}{ Sexo } & $n$ & $\%$ \\
\hline & & \\
\hline Masculino & 4 & 80 \\
\hline Feminino & 1 & 20 \\
\hline \multicolumn{3}{|l|}{ Faixa etária (falecimento) } \\
\hline $2-5$ anos & 3 & 60 \\
\hline $6-12$ anos & 1 & 20 \\
\hline$>12$ anos & 1 & 20 \\
\hline \multicolumn{3}{|l|}{ Período de seguimento } \\
\hline$<1$ ano & 1 & 20 \\
\hline $1-2$ anos & 2 & 40 \\
\hline$>2$ anos & 2 & 40 \\
\hline \multicolumn{3}{|l|}{ Tempo desde falecimento } \\
\hline $1-2$ anos & 3 & 60 \\
\hline$>2$ anos & 2 & 40 \\
\hline \multicolumn{3}{|l|}{ Local do falecimento } \\
\hline Hospital & 2 & 40 \\
\hline Domicílio & 3 & 60 \\
\hline \multicolumn{3}{|l|}{ Admissão temporária no IPO-Porto } \\
\hline Sim & 3 & 60 \\
\hline Não & 2 & 40 \\
\hline
\end{tabular}

profissional - desde o diagnóstico da doença oncológica do filho até ao presente.

\section{Impacto pessoal}

Todos os pais descreveram o diagnóstico dos filhos como algo inesperado e dramático - um "choque" que "ninguém esta preparado para ouvir" (M3). Num caso, sendo o prognóstico desfavorável ad initium, descreveu-se a sensação de "choque duplo" (M1).

"Não acredito, não pode ser verdade." (M4)

"Cai-nos tudo... Tiram-nos o chão, não é?" (M1)

“Ai, foi horrível. (...) Morri também ali.” (M2)

O diagnóstico implicou uma mudança imediata e inevitável na vida dos pais, que focalizaram todas as energias no cuidar do filho doente.
(...) a vida nunca mais é a mesma. (...)

Sem dúvida." (M1)

"Vivi para ele." (M2)

Ao longo do desenrolar da doença, ainda que conscientes da gravidade da situação, de uma forma geral os participantes mantiveram a esperança numa recuperação.

“(...) a gente acreditou sempre até ao fim.” (M5)

“(...) mesmo sabendo (...) que o fim seria uma opção certa, nunca tomámos isso como certo.” (M1)

Porém, com o agravamento da condição clínica, cada pai foi assimilando a irreversibilidade da situação e todos, no período final, se aperceberam da iminência da morte.

Chegada a hora, vários pais descreveram sentimentos de "liberdade" (M3) e de "paz" (M4), encarando o momento da partida como o fim do sofrimento do filho. A esta perda associou-se uma transfiguração interna, inevitavelmente modificadora da forma de olhar a Vida.

“(...) cresci muito. Eu não sabia muito bem esperar e aprendi a esperar muito (...) perdi o emprego.

O que é que era o emprego? (...) Pior mesmo foi quando eu perdi a saúde do meu filho." (M4)

"Agora dou é... Mais valia ao estar vivo. (...) Eu acho que estes processos só existem para nos transformar

(...) Se não, é doloroso demais, acho eu." (M3)

\section{Impacto familiar}

A família, enquanto principal elemento na prestação de cuidados da criança, ${ }^{3}$ sofreu repercussões significativas. Os avós e os irmãos destacaram-se nas entrevistas como os familiares mais afetados pela doença da criança.

"A minha mãe (...) sofreu mais. Fragilizou muito a saúde dela (...).” (M2)

"O meu filho com 5 anos ver-se sem a mãe, porque o irmão ficou doente, começou a inventar doenças, também queria vir para o hospital." (M4) "Ela [Ff] teve que ir quase todas as semanas à pedopsiquiatra (.....” (M5)

Também a relação entre os elementos do casal se modificou inevitavelmente: em quatro entrevistas referiu-se uma aproximação durante a doença, que 


TABELA 3. Resultados do Índice de Bem-Estar Pessoal.
\begin{tabular}{l|c|c|c|c|c|c|c|} 
Domínios avaliados & M1 & P1 & M2 & M3 & M4 & M5 & Média \\
\hline Nível de vida & 5 & 8 & 8 & 9 & 8 & 6 & 7,3 \\
\hline Saúde & 6 & 7 & 8 & 10 & 9 & 5 & 7,5 \\
\hline Realização pessoal & 6 & 7 & 9 & 8 & 8 & 3 & 6,8 \\
\hline Relações pessoais & 8 & 7 & 9 & 8 & 10 & 5 & 7,8 \\
\hline Sentimento de segurança & 5 & 8 & 10 & 9 & 10 & 6 & 8,0 \\
\hline Ligação à comunidade & 5 & 7 & 10 & 8 & 9 & 8 & 7,8 \\
\hline Segurança com o futuro & 5 & 8 & 10 & 9 & 8 & 5 & 7,5 \\
\hline Espiritualidade/Religião & 5 & 8 & 10 & 8 & 10 & 2 & 7,2 \\
\hline \multicolumn{1}{c|}{ Total } & 45 & 60 & 74 & 69 & 72 & 40 & 60 \\
\hline \multicolumn{1}{c}{$\%$ SM } & 56,3 & 75 & 92,5 & 86,3 & 90,0 & 50,0 & 75,0 \\
\hline
\end{tabular}

permaneceu após a partida do filho; porém, noutra foram destacadas repercussões negativas que levaram à separação.

"A nossa relação fortaleceu de outra forma (...), sentimo-nos ali os três uma peça só a viver." (M1)

"Acho que um casal nunca mais é feliz depois da doença do filho e da partida do filho, nunca mais é feliz. Acabei por me separar tambem." (M2)

\section{Impacto social}

O domínio social modificou-se acentuadamente e perdeu prioridade na vida de todos os participantes.

"Vida social acabou... Tínhamos vida social pelas redes sociais (...) pelos telefonemas e isso." (M3)

\section{Impacto profissional}

Durante a doença do filho, todos os participantes cessaram temporariamente a atividade laboral. As mães adotaram o papel de cuidadoras principais e, assim, usufruíram da licença para assistência ao filho doente (à exceção de uma que, trabalhando sem contribuições, perdeu o emprego sem direito a subsídio). Os pais viram-se obrigados a procurar outras soluções para prestar apoio presencial, por exemplo, solicitando certificado de incapacidade temporária por doença própria. Os trabalhadores independentes valorizaram a flexibilidade da sua situação que, possibilitando algum grau de atividade profissional, lhes permitia "ocupar a men- te" (M2). Como expectável, o impacto profissional repercutiu-se na estabilidade económica das famílias.

“(...) procurei baixa psicológica (...).” (P1)

“(...) ele recebia a $55 \%$ e eu a $65 \%$. Portanto, é menos um ordenado." (M1)

"Perdi o meu emprego e não tive direito a subsídio nenhum." (M4)

\section{B. Apoio}

Os tópicos emergentes das entrevistas foram codificados e classificados em categorias - apoio emocional, instrumental e informacional-, reconhecendo-se, porém, espaços de interseção entre elas.

\section{B.1. Apoio emocional}

\section{Familiares e amigos}

Todos os participantes salientaram a importância do apoio emocional prestado por entes queridos durante e após a doença. Porém, como descrito por Ml, acabou por existir uma "seleção" de "quem a gente sabia que podia contar", visto que nem todos conseguiam lidar adequadamente com a situação. $\mathrm{O}$ apoio dos que permaneceram foi valorizado e agradecido.

“[os amigos] diziam (...) "Deixa estar, isso passa. Olha, não penses nisso, olha, vai-te distrair”. Tudo coisas que era completamente ao contrário.” (M3)

“(...) a minha cunhada disse-me: 'filhinha, pensa que ele é um anjo e se ele te pediu para não chorares e 
porque quer voar à vontade (...)'. E então sempre que eu choro é de saudade, não é tristeza (...).” (M4)

\section{Equipa de profissionais de saúde}

Todos os participantes destacaram e agradeceram o respeito e a sensibilidade com que, no geral, a equipa de profissionais de saúde geriu a situação clínica do filho. Salientou-se a relação com o médico assistente (MA) e o seu potencial enquanto suavizadora do sofrimento dos pais. Os participantes destacaram também a ligação com a equipa de enfermagem, com quem muitos criaram "uma relação de amizade e de família" (M2).

“A MA para mim foi a médica (...) que tinha mais sensibilidade (...) para comunicar e conversar (...) mudou muito a forma de (...) lidar com a doença (...).” (M2)

Porém, constatou-se que nem todos os profissionais conseguiram criar uma relação de empatia sólida com as famílias que acompanhavam. Como descrito por um participante, "faltava mais ali um bocadinho daquela envolvência" (M1).

Neste âmbito da empatia, um dos tópicos que emergiu como passível de melhoria foi a comunicação de más notícias. Os moldes da comunicação do diagnóstico, apesar do drama inerente à informação partilhada, foram explicitamente descritos como desadequados em quatro das cinco entrevistas.

“(...) não houve aquele cuidado de nos resguardar um bocadinho (...)." (M1)

“(...) parece que me vieram informar de uma coisa menos grave (...)." (M2)

“(...) ela entrou pela sala (...) e disse 'mamã, vamos ter calma, desconfiamos que o seu filho tenha uma doença do foro oncológico (...)' e fecha a porta." (M4)

"Aquilo assim tipo... Muito turbilhão." (M5)

Também o contacto das famílias com as equipas do IPO do Porto, quando necessária admissão nessa unidade hospitalar, foi destacado como um ponto a melhorar. M2 descreveu o período de internamento nessa unidade como "frio" e "estranho", considerando benéfico reforçar a ligação humana entre as duas unidades hospitalares.
"Deve haver (...) uma presença do Hospital de São João... Nem que seja a visitar ou a manter ali algum conforto. (...) Não há laço nenhum.” (M2)

Segundo todos os participantes, o elo emocional desenvolvido com a equipa de profissionais do CHUSJ sofreu um claro distanciamento após a partida do filho. Alguns consideraram esta separação como prejudicial, mas outros sentiram-na necessária.

"Nós tivemos a ligação da MA. Ligou no próprio dia do funeral (...). Mas após esse telefonema, não houve grande contacto do hospital." (M1)

“(...) eu não queria voltar para ali.” (M2)

\section{Pares}

As relações de empatia, amizade e entreajuda estabelecidas entre pares - "alguém que percebe o que se esta a passar" (M1) - foram destacadas como valiosas pela maioria dos entrevistados. Vários participantes relataram a subsistência destes vínculos após a morte do filho, principalmente através das redes sociais.

"Acho que é outra família que a gente adota ali." (P1)

"Mantivemos contactos e elas vêm cá (...) ou comunicamos (...) pelo Facebook, pelo messenger." (M5)

Um participante manifestou receio perante a possibilidade de, sem orientação profissional, esta entreajuda ser perpetuadora de sofrimento. Neste sentido, em duas entrevistas sugeriu-se uma maior integração de psicólogos em grupos de apoio entre pares, sob a premissa de que a orientação de um profissional proporcionaria aos participantes uma experiência potencialmente mais confortável e eficaz.

“(...) acionar os psicólogos do hospital, com a experiência dos pais e trabalharem em conjunto." (M1)

\section{Espiritualidade e religião}

O apoio religioso oferecido durante o processo foi valorizado em quatro entrevistas, salientando-se a celebração de sacramentos urgentes e da Eucaristia no internamento, bem como o diálogo com membros da comunidade religiosa. Todos os participantes referiram que este apoio, adequado às confissões religiosas de 
cada um, pode ser uma mais-valia, devendo ser ativamente oferecido.

"Eu sobre a religião (...). Devem ir lá, devem falar. E depois cabe a cada pai (...).” (M2)

No âmbito da iniciativa «Setembro Dourado», a celebração eucarística organizada pelo serviço em memória das crianças que faleceram foi considerada por M1 como um "gesto importante" e uma oportunidade apreciada para "reencontro" com outros pais após a partida do filho.

\section{B.2. Apoio instrumental}

\section{Familiares e amigos}

O apoio da família e dos amigos mais próximos foi definido de forma unânime pelos participantes como o mais significativo nesta vertente, principalmente durante o período da doença.

"Porque sem dúvida que, se não fosse a ajuda familiar, eu sozinha não fazia nada. (...) Podia realmente tomar conta da saúde do F, mas depois não conseguia ser mãe do outro menino ou estar presente..." (M4)

No geral, o outro elemento do casal foi reconhecido como aliado perante os obstáculos. Em três entrevistas foi valorizada a cooperação do parceiro nas tarefas quotidianas, nomeadamente enquanto colaborador e/ou substituto na prestação de cuidados ao filho. Na maioria dos casos, o pai foi a principal fonte de rendimento familiar.

"Ter que pegar da cama para dar banhos (...).

Precisava imenso da ajuda dele." (M1)

“(...) uma das pessoas tem que deixar de trabalhar.

A outra tem que tomar conta de, não só da estrutura financeira, como da estrutura da casa (...).” (M3)

Outros familiares, particularmente os avós, foram valorizados enquanto substitutos dos pais à cabeceira do filho doente, em casa com os filhos saudáveis e enquanto prestadores de ajuda financeira.

“(...) ele [Ff] já estava há uma semana em casa dos meus sogros." (M3)

"Se não fosse a minha sogra (...), ele sabia que a avó que lhe dava dinheiro (...).” (M4)
Em duas entrevistas foi salientada a ajuda de entes queridos na prestação de cuidados paliativos no domicílio.

“(...) uma prima que é enfermeira (...) acionou tudo o que foi necessário, desde máquina de aspiração, máquina de oxigénio...” (M1)

Dois participantes valorizaram também a intervenção de familiares que, enquanto profissionais de saúde, agilizaram o processo de emissão do certificado médico de óbito, ultrapassando os constrangimentos inerentes às mortes no domicílio.

\section{Equipa de profissionais de saúde Apoio clínico}

Os testemunhos dos pais demonstraram unanimemente satisfação com o apoio clínico oferecido, destacando-se a disponibilidade das equipas para prestar cuidados médicos ou de enfermagem, os esforços para oferecer o melhor tratamento possível e a atenção para com as queixas das crianças.

"Dentro daquilo que os profissionais puderam fazer, tivemos noção de que fizeram tudo o que estava ao alcance deles." (M1)

Todos valorizaram também os esforços da equipa no sentido de adaptar a estratégia de atuação consoante as necessidades e desejos da criança doente e da sua família. Salientaram-se a flexibilização das regras que orientam as visitas hospitalares e a possibilidade de prestar cuidados no domicílio.

“(...) eles permitiam visitas, como era um dito 'caso especial' (...).” (M1)

"E ele $[\mathrm{F}](. .$.$) 'porque é que vocês não vão$ a minha casa?' e a Dra disse 'Mas nós podemos ir a tua casa (...). Se é o teu conforto, nós só te queremos ver bem." (M4)

\section{Apoio psicológico}

De uma forma geral, os participantes sentiram algumas lacunas no apoio psicológico oferecido a nível hospitalar, descrevendo-o como não atempado e muito dependente da iniciativa dos progenitores. De salientar que os pais que sofreram a perda mais recente receberam acompanhamento psiquiátrico.

"A mim nunca me encaminharam [para psicologia].” (M3) 
"Eu recordo-me que nos foi dito assim uma frase (...) 'se precisarem de ajuda psicológica, digam que nós acionamos' (...). Nem estamos a pensar em nós (...) pensamos nele. Nem acionámos nada.” (M1) “(...) tive sempre resposta, mas porque eu solicitava." (M2)

“(...) encaminharam-nos logo para a (...) psiquiatra (...) para digerir esta situação.”(M5)

Apresentaram-se algumas sugestões de melhoria: investigação ativa, junto dos pais, sobre a necessidade deste apoio, acionando as ajudas ad initium ou sempre que pertinente, salvaguardando-se o respeito pela recusa; criação de um gabinete onde os pais pudessem procurar e receber este tipo de apoio.

“(...) até devia haver mais... interesse na equipa (...). Em perceber como é que os pais estão." (M2) "Eu acho que deveria ser imediatamente acionado.” (M1)

“(...) era muito, muito importante haver (...). Um confessionário basicamente, sem ser (...) religioso. Em que nós pudéssemos [falar].” (M3)

\section{Cuidados de saúde primários (CSP)}

Apesar de não terem desempenhado um papel de destaque em nenhum dos casos entrevistados, um participante destacou a importância que os CSP, pela sua proximidade, poderiam ter após a morte, enquanto facilitadores do processo de luto (inclusive através da prestação de apoio psicológico).

“(...) esse interesse no médico de família

com... Ou um psicólogo ligado a ele (...).

Essa articulação devia existir. Mas na localidade da pessoa. (...) Isso é dar importância.” (M2)

\section{Cuidados paliativos domiciliários}

Todos os participantes descreveram positivamente a prestação de cuidados domiciliários ao filho em fim de vida. Para a sua capacitação consideraram fundamental o suporte profissional clínico que sentiram por via telefónica e através das deslocações regulares da equipa de profissionais ao domicílio para prestação de cuidados diferenciados. Este suporte profissional domiciliar resulta de uma parceria entre a Fundação do Gil e vários hospitais públicos do país (um dos quais, o CHUSJ) e baseia-se em equipas de cuidados domici- liários pediátricos (CDP) que integram vários profissionais de saúde. ${ }^{37}$

"Nós assumimos fazer os paliativos em casa e eu tinha uma lista que era revista de dois em dois dias, (...) vinha geralmente uma enfermeira e uma médica. (...) Mas nós éramos totalmente responsáveis por administrar mais ou menos (...). E isso eu achei bem. Criarem-nos a nós essa responsabilidade e essa confiança (...).” (M3)

Nesta sequência foi abordada numa entrevista a questão da eutanásia. Segundo M3, “(...) nem sequer tivemos de pensar nisso, porque todo o processo da F foi super calmo."

\section{Técnicos de ação social}

De uma forma geral, os serviços de apoio social do CHUSJ - Unidade de Ação Social (UAS) do Serviço de Humanização - foram considerados úteis durante a doença, principalmente enquanto facilitadores da gestão burocrática inerente à ativação dos recursos sociais disponíveis.

"A nível da segurança social havia um mini gabinete, com uma pessoa sempre lá presente para tratar da parte burocrática toda. (...) Eles trataram de tudo..." (M3)

Contrariamente, todos os pais entrevistados demonstraram, de uma forma geral, descontentamento com o apoio oferecido pela estrutura social a nível nacional. Destacaram-se negativamente as dificuldades encontradas na obtenção de licenças e subsídios, que consideraram insuficientes.

"Davam-me 92€para eu estar em casa com ela a $100 \%$. Quer dizer, não era esse dinheiro, de todo." (M3)

"Tive de me deslocar até à segurança social

(...) para avaliar se o $\mathrm{F}$ realmente precisava de uma pessoa para cuidar dele. E ridículo. (...) Tivemos que o levar." (M1)

\section{Associações de voluntariado}

A maioria dos participantes destacou a ajuda da associação Acreditar (Associação de Pais e Amigos de Crianças com Cancro) durante o período da doença a três níveis: ação de voluntariado no serviço, ajudas 
materiais/financeiras e suporte na gestão da burocracia.

“(...) eles diziam: 'Vão almoçar, saiam lá fora.

Nós ficamos com os meninos'. (...) Isso e de louvar (...)." (M1)

“(...) ele precisou de (...) uma cadeira (...). Eles arranjaram." (M5)

"Tive a instituição Acreditar (...). Para mim foi... A chave (...). A medicação para o F nunca faltou, (...) arranjei sempre graças a essas pessoas (...).” (M4)

\section{Infraestruturas}

Sobre o internamento de pediatria (conhecido por Joãozinho), construído a partir de contentores no exterior do edifício principal do CHSJ, os pais, na sua totalidade, referiram que não era "agradável" (M3), "não chegava” (M2), "não tinha condições” (P1).

\section{B.3. Apoio informacional}

\section{Equipa de profissionais de saúde}

Os profissionais de saúde, a nível hospitalar, foram descritos como os principais fornecedores deste apoio, por exemplo, através da comunicação de informação clínica, da explicação das etapas do processo, da discussão de hipóteses de tratamento ou do esclarecimento de dúvidas.

"E ela [MA] (...) trocava opiniões comigo. (...). E dava-me os prós e os contras." (M2)

Uma adequada comunicação clínica possibilitou que os pais se sentissem mais integrados e preparados para lidar com o que foi sucedendo. Um participante referiu como benéfica a centralização desta comunicação num só profissional de saúde, nomeadamente no médico assistente.

“(....) [A MA] falou explicitamente do dia da morte, da hora da morte, dos cuidados que ela poderia ter. (...) Por isso, ela alertou-nos para isso tudo." (M3)

“(...) a Dra , para mim, era a única que me devia passar as informações (...), como médica responsável dele

(...). E tem que ser, só central.” (M2)

Apesar de satisfeitos com as informações prestadas sobre recursos disponíveis durante a doença, foram percetíveis lacunas na partilha de recursos existentes para suporte no período após a morte do filho, sendo que três participantes negaram ter recebido qualquer informação sobre apoio ao luto.

“(...) por iniciativa minha, procurei. (...) porque é claro que a gente precisa de alguma ajuda. A gente nem sabe (...) Onde recorrer." (M1) "Agora, nunca me falaram, nunca me disseram, nem depois na parte do velório, 'Olhe, pode falar com aquela pessoa (...)'.” (M3)

\section{DISCUSSÃO}

Os testemunhos colhidos ao longo das cinco entrevistas com pais que perderam um filho em idade pediátrica devido a doença oncológica permitiram iluminar a subjetividade desta realidade. Cada testemunho - marcadamente pessoal e íntimo - ilustrou uma experiência única, inserida num contexto individual.

Segundo Marques, ${ }^{3}$ a doença oncológica de uma criança ou jovem apresenta múltiplas repercussões na família, obrigando a uma reestruturação da dinâmica familiar (com influência nas relações entre o casal, os filhos saudáveis e o filho doente), alterando substancialmente as prioridades (com prejuízo das atividades sociais) e gerando instabilidade económica por perda de rendimento e aumento de despesas. Os testemunhos partilhados pelos participantes neste estudo alinham-se com estas conclusões.

O diagnóstico de doença oncológica foi recebido por todos os entrevistados como inesperado e dramático, acarretando uma transformação imediata do Eu, que passou a viver em torno de outrem, sacrificando a sua individualidade. A ideia transversalmente disseminada na sociedade de que a doença oncológica é prenúncio de morte, após grande e prolongado sofrimento, é inevitavelmente considerada, ${ }^{15}$ amplificando os medos de cada um.

Como sucede na generalidade dos casos, todas as mães entrevistadas adotaram o papel de cuidador principal do filho doente, relegando para segundo plano outras responsabilidades familiares ou profissionais. Por outro lado, a figura paterna, ainda muito associada ao "sustento da família", confronta-se com um dilema - cuidador ou fonte de apoio económico ${ }^{38}$ Nos casos entrevistados constataram-se ambas as realidades: pais que adotaram o papel de suporte financeiro e pais que 
optaram por cessar temporariamente a atividade profissional para participarem ativamente no cuidar do filho. Para mães e pais, a carreira e a vida social passaram a secundários.

Em sintonia com o encontrado na literatura, todos os entrevistados (à exceção de um) revelaram um fortalecimento dos laços com o outro progenitor do filho durante o período de doença e fim de vida. Tal aproximação pode justificar-se pelo esforço conjunto e pelo apoio mútuo para alcançar um objetivo comum - o bem-estar do filho.$^{38}$ Com a partida deste, a missão cessa. Talvez por isso haja autores que referem um risco significativo de divórcio. ${ }^{39}$

A doença oncológica, pela sua cronicidade, acarreta perdas que se sucedem e que obrigam a um luto antecipatório. Medo, negação, impotência, culpa ou raiva são sentimentos de luto que podem surgir ainda em vida do filho e que podem propiciar o desenvolvimento de psicopatologia grave. ${ }^{6,10,12,19,39-42}$ Tal legitima a abordagem presente durante as entrevistas: o foco não foi apenas o período pós morte e o luto propriamente dito; considerou-se indispensável acompanhar também os lutos pelas várias perdas sofridas desde o início do processo.

Neste caminhar progressivo para o fim, apesar de cientes do prognóstico desfavorável da situação clínica do filho, todos os entrevistados referiram ter-se agarrado à ideia de que tudo ainda se poderia reverter. Porém, à semelhança do reconhecido na literatura, ${ }^{43}$ perante o definhar incontestável do filho, também todos acabaram por aceitar a iminência da morte.

Chegado o momento, com a partida do filho os pais perderam o epicentro em torno do qual giravam, o seu propósito. Iniciaram então uma nova fase de ser e estar (sem fim), na qual tentam adaptar-se à ausência física do filho e manter vivo o vínculo afetivo que os unia. ${ }^{6}$ A saudade, como expectável, foi destacada transversalmente pelos participantes, mas a singularidade de cada testemunho confirmou que o percurso até uma adaptação à nova realidade é deveras dinâmico e individual. ${ }^{8,19,39}$

\section{Apoio}

Descritos na literatura como os domínios de apoio mais valorizados pelos pais em luto, ${ }^{20-23}$ considera-se que a otimização do apoio prestado a nível emocio- nal, instrumental e informacional será essencial para suavizar o viver e o sobreviver a esta experiência penosa.

\section{Apoio emocional}

\section{Familiares e amigos}

O círculo de família e amigos próximos ocupou, em todas as entrevistas, o lugar de destaque enquanto fonte de suporte emocional. Com a doença da criança adoece também a família. Conhecer esta rede de apoio pode ajudar a identificar potenciais aliados no cuidar da família doente.

\section{Equipa de profissionais de saúde}

A relação dos pais com os profissionais de saúde influencia significativamente o seu viver desta realidade. ${ }^{44}$ Sobre este ponto, ressaltou em todas as entrevistas a necessidade de demonstrar empatia desde o momento da comunicação do diagnóstico, per se uma experiência dramática. Foi transversalmente considerado que os moldes em que se procedeu à partilha do diagnóstico deveriam ser melhorados. Porém, comunicar notícias difíceis é uma tarefa árdua, que obriga o médico a confrontar-se com as próprias emoções. ${ }^{21,45} \mathrm{Con}$ sidera-se, então, pertinente investir na capacitação dos profissionais de saúde, por exemplo, através de formação na área de competências clínicas de comunicação. Fornecer-lhes ferramentas úteis para organização mental do processo e para gestão das emoções dos intervenientes (incluindo o próprio stress), favorecendo o sucesso da comunicação. ${ }^{46}$

Ao longo do acompanhamento hospitalar, os laços entre os pais e alguns profissionais de saúde vão-se reforçando. ${ }^{44}$ No geral, todos os participantes referiram uma relação de proximidade com o pessoal médico, principalmente com o médico assistente. Destacaram também a ligação com a equipa de enfermagem que, pelos cuidados que presta, tem um contacto mais próximo com o doente e respetivas famílias. Assim, é papel dos médicos e enfermeiros acompanhar atentamente os pais, detetando situações preocupantes que obriguem a intervenção de outras áreas (como psicologia ou assistência social).

Estes laços, suavizadores da vivência hospitalar das famílias, são por elas muito valorizados. Portanto, quando a criança necessita de uma admissão 
temporária noutra unidade hospitalar, onde todos voltam a ser desconhecidos, as famílias sofrem com uma nova solidão, como enfatizado num testemunho sobre o internamento no IPO do Porto. Considera-se, assim, relevante implementar processos de comunicação entre os profissionais envolvidos que garantam uma robusta $\mathrm{e}$ eficaz articulação entre serviços e unidades de saúde.

Com a morte da criança/jovem doente, a ligação entre a família e o hospital modifica-se. Se existem pais que preferem um corte definitivo após a morte do filho, para outros é importante manter o contacto com o hospital. Quando tal não acontece, sentem que, juntamente com o filho que perderam, foram abandonados e esquecidos. ${ }^{44}$ Nos testemunhos colhidos descreveu-se a presença (nem sempre física) da equipa de profissionais de saúde até às cerimónias fúnebres. Alguns participantes referiram posteriores telefonemas esporádicos e contactos casuais através das redes sociais, não sentindo, porém, uma presença ativa da equipa nesta nova realidade. Contudo, reconhece-se a importância de uma desvinculação gradual e, de uma forma geral, considera-se importante que a unidade hospitalar demonstre a todos os pais disponibilidade para manter a ligação. ${ }^{44}$

\section{Pares}

A maioria dos participantes destacou a importância dos laços estabelecidos com pais a viver situações semelhantes, concordante com o descrito na literatura. ${ }^{47} \mathrm{Sa}-$ lientaram as relações de amizade com outros pais que conheceram neste contexto e que formaram uma importante rede de apoio - segundo P1, uma família adotada.

Perante alguém que os compreende deveras, os pais sentem que podem exteriorizar livremente as suas emoções, sem julgamentos. ${ }^{47} \mathrm{~A}$ ajuda entre pares, através de grupos de entreajuda, por exemplo, considera-se uma eficaz arma terapêutica, propiciando uma evolução mais favorável do luto. ${ }^{43}$ Neste sentido, considera-se que a entidade hospitalar deve investir em projetos que, mediados por equipas multidisciplinares, incentivem a interação entre pares.

\section{Espiritualidade/religião}

De uma forma geral, a partida física de um filho leva à procura de uma presença sob outra forma e de um significado para essa perda. ${ }^{48-49}$ Intimamente relacionada com a espiritualidade de cada pai, esta procura insere-se numa estratégia de coping potencialmente protetora. ${ }^{48-49} \mathrm{O}$ CHUSJ assegura uma assistência espiritual e religiosa plural através do seu serviço religioso; porém, deve criar condições para que este tenha uma presença mais visível e proativa junto dos serviços clínicos, ultrapassando as dificuldades inerentes à procura do mesmo na Capelania.

\section{Apoio instrumental \\ Familiares e amigos}

Todos os participantes consideraram importantes as ajudas práticas dos familiares e amigos ao longo do processo, destacando o papel preponderante dos avós. Os contributos salientados incluem apoio aos filhos saudáveis, ajudas com a manutenção da casa e suporte financeiro. É importante que as equipas se mantenham atentas a eventuais lacunas - por exemplo, ausência de apoio familiar - para que as possam colmatar atempada e adequadamente.

\section{Equipa de profissionais de saúde Apoio clínico}

Todos os entrevistados destacaram positivamente $o$ apoio clínico oferecido pela equipa de profissionais de saúde, demonstrando gratidão para com os seus elementos. Inicialmente, e à semelhança do descrito na literatura, o acompanhamento hospitalar marcou-se pela priorização da intervenção curativa e, nesse sentido, pelo foco nos cuidados prestados pela equipa de profissionais. Contudo, a progressiva familiarização dos progenitores com a doença e com o sistema hospitalar permitiu-lhes compreender mais amplamente o seu papel na tríade assistencial doente/profissional de saúde/pais. Registou-se, então, uma integração gradual dos participantes na prestação de cuidados, visando o cumprimento pleno do seu papel de pais e, portanto, cuidadores. ${ }^{44}$ Esta sensação de integração e o trabalho colaborativo foram muito valorizados em todas as entrevistas, devendo ser sempre incentivados. Encontram o seu expoente máximo na capacitação dos pais para prestar cuidados ao filho no domicílio.

\section{Apoio psicológico}

A integração da equipa de psicologia no acompanhamento do processo foi descrita, pela maioria dos 
participantes, como tardia, muito dependente da iniciativa dos pais e passível de melhoria.

As intervenções psicossociais criam um dilema na família: focar a atenção na criança doente versus focá-la na família «doente». ${ }^{50} \mathrm{Tal}$ justifica, em parte, a dificuldade dos pais em solicitar ajuda. Quando oferecida ativamente, estes podem nem a aceitar por ignorarem as próprias emoções. Contudo, sabe-se que uma intervenção com início nos primeiros meses e mantida ao longo do tempo (com as devidas adaptações e de acordo com a evolução de cada um) é valorizada pelos pais. ${ }^{50}$ Assim, sugere-se uma abordagem mais proativa junto das famílias.

No caso do SOP do CHUSJ, a equipa conta apenas com um elemento de psicologia, que trabalha predominantemente com as crianças e jovens doentes. ${ }^{51}$ É, então, necessário recrutar mais psicólogos para o serviço, potenciando a multidisciplinaridade requerida para a equipa assistencial em oncologia pediátrica. Considera-se particularmente interessante a formação de uma equipa de especialistas (psicólogos, psicoterapeutas) apenas dedicada a trabalhar em proximidade com pais e/ ou cuidadores de doentes paliativos pediátricos.

Se no período de doença e fim de vida o apoio é fundamental para preparar a partida, este apoio adquire ainda mais relevância aquando do derradeiro luto. Porém, à exceção de um casal seguido temporariamente por psiquiatria (M5 e P5), nenhum outro participante recebeu apoio psicológico ou psiquiátrico do hospital após a morte.

A responsabilidade da entidade hospitalar a este nível não deve terminar após o falecimento do doente; assim, as equipas devem promover um follow-up das famílias, estabelecendo contactos com os pais no intuito de perscrutar as suas necessidades, ${ }^{4}$ inclusive a nível psicológico. Não sendo possível (ou desejado pelos pais) manter esta ligação com o hospital, poder-se-ia solicitar a colaboração de outras entidades de saúde.

\section{Cuidados de saúde primários}

Pela proximidade geográfica e pessoal que lhes é inerente, os CSP estão bem posicionados para acompanhar as famílias durante a doença da criança/jovem e após a sua morte; porém, nenhum dos participantes mencionou qualquer intervenção por parte destes. Perante tamanha provação à saúde familiar, faz todo o sentido integrar na rede de apoio os médicos e enfermeiros de família, bem como as equipas de psicologia dos CSP. Esta integração torna-se principalmente pertinente após a morte da criança/jovem, como referido por um participante, pelo "corte" existente com a unidade hospitalar - tanto pelo fim do acompanhamento clínico como pelas memórias que se pretendem evitar.

Assim, considera-se que a entidade hospitalar deve aproveitar os elos já estabelecidos com os CSP para incentivar a sua atuação neste contexto e que estes, por sua vez, devem adotar uma atitude proativa, atenta e diligente na abordagem e acompanhamento destas famílias em luto.

\section{Cuidados paliativos domiciliários}

Todos os participantes usufruíram deste tipo de cuidados e participaram ativamente nos mesmos, destacando como principais vantagens o conforto do lar e a autonomia sentida. Esta perceção de autonomia assenta num apoio clínico sempre disponível por chamada telefónica e em regulares visitas domiciliárias pelas equipas de CPD. Estas equipas, muito valorizadas pelos entrevistados, auxiliam na administração terapêutica e no controlo dos sintomas, potenciando o conforto e a proteção da criança/jovem doente. ${ }^{37}$ De facto, além da satisfação dos progenitores, geralmente as crianças também se sentem melhor quando recebem cuidados no domicílio, alcançando melhores outcomes a longo prazo. ${ }^{52}$ Considera-se, então, importante continuar a investir em projetos que, como os CPD, potenciem a autonomia e o conforto durante este processo penoso.

É nesta sequência que, numa das entrevistas, se aborda a temática da eutanásia, um dilema ético que pode emergir perante este cenário. No testemunho partilhado, a família nega ter sequer ponderado essa hipótese, por sentir que o processo se desenrolou com naturalidade, garantindo-se sempre um controlo adequado dos sintomas da criança. Ao possibilitarem uma melhoria significativa na qualidade de vida da "unidade de cuidados" (constituída pela criança e sua família), ${ }^{53}$ os CPD sobrepõem-se à ideia de antecipação da morte como única solução para alívio do sofrimento. Assim, considera-se que Portugal deve continuar a unir esforços, como tem feito nos últimos anos, no sentido de desenvolver esta vertente de cuidados. 


\section{Técnicos de ação social}

O contacto com a UAS do CHUSJ recebeu, no geral, uma apreciação positiva pela ajuda com a gestão da burocracia, pelo esclarecimento de dúvidas e pela divulgação de direitos e recursos disponíveis, bem como dos processos para os obter.

Porém, fora do hospital sentiram-se marcadas dificuldades nos processos de obtenção de ajudas sociais, que, por sua vez, se consideraram desadequadas. Destacaram-se apoios financeiros insuficientes que, associados a cortes significativos nos rendimentos, contribuíram para conjunturas familiares desfavoráveis. Mantendo-se durante os vários meses de evolução da doença, estas conjunturas ameaçam a estabilidade financeira das famílias, abalando, consequentemente, toda a estrutura familiar. ${ }^{3}$ As instâncias superiores têm, recentemente, estruturado projetos que visam a melhoria desta situação. Porém, considera-se pertinente que o CHUSJ, enquanto entidade hospitalar, reforce as pontes burocráticas já existentes, nomeadamente com os serviços de segurança social, no sentido de eliminar alguns dos obstáculos que os pais enfrentam neste processo.

\section{Associações de voluntariado}

A maioria dos participantes destacou nos seus testemunhos o papel da associação Acreditar, cuja missão inclui cuidar da criança com cancro e da sua família, providenciando suporte nos planos emocional, logístico e social. ${ }^{54}$ Valorizou-se particularmente a intervenção em três vertentes: voluntariado hospitalar (proporcionador de descanso aos cuidadores), esclarecimento de dúvidas técnicas e apoio na gestão burocrática, oferta de ajuda financeira e material. Parcerias como esta representam uma mais valia para a entidade hospitalar e para todos os diretamente envolvidos na rede de cuidados à criança/jovem doente, devendo, pois, ser incentivadas.

\section{Infraestruturas}

As infraestruturas na altura destinadas ao internamento do SOP foram destacadas negativamente em todas as entrevistas. Reconhecendo-se esta fragilidade, a recente mudança para um novo serviço no edifício principal do CHUSJ procurou atenuar as dificuldades expressas pelos pais, enquanto se aguarda a con- clusão das instalações finais perspetivadas para o serviço.

\section{Apoio informacional \\ Equipa de profissionais de saúde}

Como descrito na literatura, a equipa de profissionais de saúde foi considerada a principal fonte de apoio informacional, ${ }^{21}$ sendo que os participantes, no geral, consideraram-se adequadamente informados e esclarecidos sobre a condição clínica do filho e as várias etapas do processo. Salientou-se o papel dos médicos na comunicação da informação clínica, valorizando-se a disponibilidade para discutir ideias e hipóteses de tratamento. Sugeriu-se a existência de um único canal de comunicação - nomeadamente, o médico assistente responsável por partilhar toda a informação pertinente.

Satisfeitos com o apoio informacional oferecido, os participantes sentiram-se mais preparados para o que ia sucedendo, mais integrados na equipa e mais capacitados para tomar decisões sobre os cuidados ao filho doente. Estes testemunhos alinham-se com o modelo de prática clínica que tem vindo a ser implementado nas últimas décadas e que pressupõe uma relação médico-doente (neste caso, médico - pai/mãe do doente) baseada na cooperação, no poder partilhado e na responsabilidade mútua. ${ }^{55}$

Reconhece-se a importância da orientação institucional durante o processo de luto parental; ${ }^{56}$ porém, de uma forma geral, os participantes não foram informados sobre os apoios disponíveis após a morte do seu filho. Considera-se, então, fundamental que a entidade hospitalar direcione esforços no sentido de, através de uma equipa multidisciplinar, identificar os variados recursos disponíveis para apoiar o luto parental (e.g., livros, grupos de apoio, associações), avaliando a relevância e qualidade de cada um. Partilhar uma lista de recursos disponíveis e adequados às necessidades de cada progenitor seria um contributo importante para uma experiência de luto mais saudável.

\section{Índice de Bem-Estar Pessoal}

Os resultados obtidos a partir da aplicação deste índice foram tendencialmente positivos, demonstrando satisfação dos progenitores com a sua vida atual. A média dos valores calculados foi de $75,5 \% \mathrm{SM}$, superior ao 
descrito na literatura para a população portuguesa (68,9\%SM) e em linha com a média dos países ocidentais. Foi notória uma tendência para valores mais elevados com o maior distanciamento temporal à perda.

Apesar de se reconhecer que não existe uma contribuição proporcional de cada item, ${ }^{35} \mathrm{o}$ valor médio calculado afigura-se paradoxal perante uma vivência tão dramática. Por um lado, pode justificar-se pela adoção de estratégias que permitem a estes pais "bem viver" com o que os rodeia, como refere Rebelo, ${ }^{43}$ por exemplo, priorizando e valorizando as relações interpessoais. Por outro lado, pelas limitações metodológicas do estudo, considera-se a hipótese de apenas terem aceitado participar pais com maior grau de bem-estar.

\section{Limitações}

A seleção dos participantes por conveniência - pela qual os autores do presente estudo optaram por constrangimentos temporais e geográficos - é uma estratégia não probabilística que introduz um viés de seleção. Os participantes demonstraram grande abertura e capacidade de distanciamento para abordar criticamente os acontecimentos; porém, os pais que não aceitaram participar podem ter tido experiências muito distintas, pelo que os resultados alcançados apenas podem ser generalizados para a amostra estudada, comprometendo a validade externa das conclusões. ${ }^{57}$

A investigadora principal esforçou-se por transcrever as intervenções de todos os interlocutores verbatim, mantendo as interjeições e as hesitações ou interrupções (simbolizadas por reticências) para minimizar a introdução de vieses.

No que respeita à análise do conteúdo das transcrições, que incluiu a sua codificação e categorização, deve considerar-se a subjetividade inerente ao processo qualitativo: existem infinitas possibilidades para categorização de conteúdos e, portanto, existem inevitavelmente variações de investigador para investigador. ${ }^{58}$

Reconhece-se que um reduzido número de participantes pode ser uma falha no estudo; porém, o tamanho amostral ideal em estudos qualitativos não é consensual e depende de diversos fatores. ${ }^{59}$ Assim, pela delicadeza do tema, os autores consideraram o número de participantes expressivo, sendo qualquer testemunho, crítica ou sugestão de extremo valor.
Posto isto, não obstante as limitações expostas, os presentes resultados mantêm-se pertinentes e não dispensam uma reflexão séria sobre a temática.

\section{CONCLUSÃO}

Neste estudo descreveram-se as experiências de vários pais que perderam um filho em idade pediátrica por doença oncológica, salientando a singularidade de cada uma e compilando as necessidades mais prementes que emergiram dos testemunhos. Concluiu-se que os apoios prestados pela entidade hospitalar - vertentes emocional, instrumental e informacional - se dirigiram especialmente para o período de doença e fim de vida (luto antecipatório), com prejuízo do luto após a morte do filho doente. Destacaram-se pontos muito fortes nos apoios já implementados, valorizados pelos pais entrevistados, nos quais é meritório continuar a investir. Por outro lado, delinearam-se recomendações de melhoria nas vertentes de comunicação de más notícias, articulação com outras unidades de saúde ou de ação social e no apoio psicológico, visando contribuir para a implementação plena da Carta de Humanização do CHUSJ. ${ }^{60}$

Assim, é importante realizar estudos semelhantes (colmatando as limitações acima expostas) para uma melhor perceção daquilo que se faz noutras entidades hospitalares do país, permitindo um diagnóstico de situação mais preciso para delinear estratégias de melhoria. Acredita-se que, à semelhança do que tem sido feito em vários países ${ }^{14,24,26-27,31}$ e dos esforços que o SOP do CHUSJ tem levado a cabo, o futuro passará pelo investimento nos cuidados paliativos pediátricos e pela estruturação de programas formais de apoio ao luto parental antecipatório, com continuidade após a perda do filho doente.

\section{AGRADECIMENTOS}

Os autores agradecem à Dra. Ana Paula Fernandes, na condição de Profissional de Ligação do Serviço de Oncologia Pediátrica do Centro Hospitalar Universitário de São João, a colaboração no processo de seleção e contacto dos participantes.

\section{REFERÊNCIAS BIBLIOGRÁFICAS}

1. Barreto $X$, Correia JP, Cunha $O$, editors. A mortalidade infantil em Portugal: evolução dos indicadores e factores associados entre 1988 a 2008. Lisboa: Fundação Francisco Manuel dos Santos; 2014. ISBN 9789898662248 
2. Rubin SS. The death of a child is forever: the life course impact of child loss. In: Stroebe MS, Stroebe W, Hansson RO, editors. Handbook of bereavement: theory, research and intervention. Cambridge University Press; 1993. p. 285-99.

3. Marques G. O impacto da doença oncológica da criança na família. Porto: Afrontamento; 2017. ISBN 9789723615319

4. Levick J, Fannon J, Bodemann J, Munch S, Ahern K. NICU bereavement care and follow-up support for families and staff. Adv Neonatal Care. 2017;17(6):451-60.

5. Himelstein BP, Hilden JM, Boldt AM, Weissman D. Pediatric palliative care. N Engl J Med. 2004;350(17):1752-62.

6. Denhup CY. A new state of being: the lived experience of parental bereavement. Omega J Death Dying. 2017;74(3):345-60.

7. Bergstraesser E, Inglin $S$, Hornung R, Landolt MA. Dyadic coping of parents after the death of a child. Death Stud. 2015;39(1-5):128-38.

8. Parkes CM, Prigerson HG. Bereavement: studies of grief in adult life. 4th ed. New York: Penguin; 2010. ISBN 9780141049410

9. Prigerson HG, Maciejewski PK. Grief and acceptance as opposite sides of the same coin: setting a research agenda to study peaceful acceptance of loss. Br J Psychiatry. 2008;193(6):435-7.

10. Rando TA. An investigation of grief and adaptation in parents whose children have died from cancer. J Pediatr Psychol. 1983;8(1):3-20.

11. Institute of Medicine, Committee on Palliative and End-of-Life Care for Children and Their Families, Field MJ, Behrman RE, editors. When children die: improving palliative and end-of-life care for children and their families [Internet]. Washington: National Academies Press; 2003. Available from: https://pubmed.ncbi.nlm.nih.gov/25057608/

12. Melo R. Processo de luto: o inevitável percurso face a inevitabilidade da morte [Internet].2004. Available from: http://nda.tecnico.ulisboa.pt/ files/sites/40/Luto.pdf

13. Marques M. Fatores que impedem a resolução do luto. Psicologia.pt O portal dos psicólogos [Internet]; 2015. Available from: http://www. psicologia.pt/artigos/textos/A0860.pdf

14. Inati V, Matic M, Phillips C, Maconachie N, Vanderhook F, Kent AL. A survey of the experiences of families with bereavement support services following a perinatal loss. Aust N Z J Obstet Gynaecol. 2018;58 (1):54-63.

15. Gomes R, Pires AA, Moura MJ, Silva LI, Silva SA, Gonçalves M. Comportamento parental na situação de risco do cancro infantil. Anal Psicol. 2004;22(3):519-31.

16. Gupta S, Rivera-Luna R, Ribeiro RC, Howard SC. Pediatric oncology as the next global child health priority: the need for national childhood cancer strategies in low- and middle-income countries. PLoS Med. 2014;11(6):e1001656.

17. World Health Organization. Childhood cancer [homepage].WHO; 2021. Available from: https://www.who.int/news-room/fact-sheets/detail/ cancer-in-children

18. Boman K, Lindahl A, Björk O. Disease-related distress in parents of children with cancer at various stages after the time of diagnosis. Acta Oncol. 2003;42(2):137-46.

19. Santos RC, Yamamoto YM, Custódio LM. Aspectos teóricos sobre o processo de luto e a vivência do luto antecipatório. Psicologia.pt - O portal dos psicólogos [Internet]; 2018. Available from: https://www. psicologia.pt/artigos/textos/A1161.pdf
20. Price J, Jordan J, Prior L, Parkes J. Living through the death of a child: a qualitative study of bereaved parents' experiences. Int J Nurs Stud. 2011; 48(11):1384-92.

21. Gijzen S, L'Hoir MP, Boere-Boonekamp MM, Need A. How do parents experience support after the death of their child? BMC Pediatrics. 2016;16(1):204.

22. Toller PW. Bereaved parents' experiences of supportive and unsupportive communication. South Comm J. 2011;76(1):17-34.

23. Thuen F. Social support after the loss of an infant child: a long-term perspective. Scand J Psychol. 1997;38(2):103-10.

24. Boston Children's Hospital. Bereavement program [homepage]. Boston: Boston Children's Hospital. Available from: https://www.childrenshospital.org/patient-resources/holistic-medicine/bereavement-program

25. The Royal Children's Hospital Melbourne. Palliative care: bereavement [homepage]. Melbourne: The Royal Children's Hospital Melbourne. Available from: https://www.rch.org.au/rch_palliative/for_health_ professionals/Bereavement/

26. Child Bereavement UK. Child bereavement UK.org [homepage]. Available from: https://www.childbereavementuk.org/

27. Chambers L.A guide to children's palliative care: supporting babies, children and young people with life-limiting and life-threatening conditions and their families [homepage]. 4th ed. Bristol: Together for Short Lives; 2018. Available from: https://www.togetherforshortlives.org.uk/ resource/a-guide-to-childrens-palliative-care/

28. World Health Organization. Palliative care [homepage]. WHO; 2011. Available from: https://www.who.int/cancer/palliative/definition/en/

29. International Children's Palliative Care Network. Global levels of CPC provision: ICPCN estimated levels of children's palliative care provision worldwide [homepage]. ICPCN; 2019. Available from: http://www.icpcn .org/1949-2/

30. Knapp C, Woodworth L, Wright M, Downing J, Drake R, Fowler-Kerry S, et al. Pediatric palliative care provision around the world: a systematic review. Pediatr Blood Cancer. 2011;57(3):361-8.

31. Connor SR, Bermedo MC, editors. Global atlas of palliative care at the end of life. Worldwide Palliative Care Alliance; 2014. ISBN 9780992827700

32. Jones ML, Kriflik GK, Zanko M. Grounded theory: a theoretical and practical application in the Australian film industry [homepage]. In: Hafidz Bin A, editor. Proceedings of the International Qualitative Research Convention 2005 (QRC05). Malaysia: Qualitative Research Association of Malaysia; 2005. Available from: https://ro.uow.edu.au/commpapers/46/

33. Crowe S, Cresswell K, Robertson A, Huby G, Avery A, Sheikh A. The case study approach. BMC Med Res Methodol. 2011;11:100.

34. Kaplan B, Maxwell JA. Qualitative research methods for evaluating computer information systems. In:Anderson JG, Aydin CE, editors. Evaluating the organizational impact of healthcare information systems. New York: Springer; 2005. p. 30-55. ISBN 9780387303291

35. Pais-Ribeiro J, Cummins R. O bem-estar pessoal: estudo de validação da versão portuguesa da escala. In: Leal I, Pais-Ribeiro J, Silva I, Marques S, editors. Actas do 7o Congresso Nacional de Psicologia da Saúde. Lisboa: Edições ISPA; 2008. p. 505-8. ISBN 9728400828

36. Harrell MC, Bradley MA. Data collection methods: semi-structured interviews and focus groups [homepage]. Santa Monica: RAND Corpora- 
tion; 2009. Available from: https://www.rand.org/pubs/technical_reports/TR718.html

37. Fundação do Gil. Cuidados domiciliários pediátricos [homepage]. Lisboa: Fundação do Gil. Available from: https://fundacaodogil.pt/projectos/\#cuidados-domiciliarios

38. Brody AC, Simmons LA. Family resiliency during childhood cancer: the father's perspective. J Pediatr Oncol Nurs. 2007;24(3):152-65.

39. Rebelo JE. Contributos para o estudo do processo de luto [dissertation]. Porto: Universidade Fernando Pessoa; 2003.

40. Bernardes IA, Pegoraro RF. Irmãos saudáveis de criança com câncer: revisão integrativa da literatura [Brothers of healthy child with cancer: integrative review of literature]. Espaç Saúde. 2015;16(4):98-108. Portuguese

41. Kübler-Ross E, Wessler S, Avioli LV. On death and dying. JAMA. 1972;221 (2):174-9.

42. Correia MA. Luto antecipatório na doença oncológica: estudo exploratório com o Marwit-Meuser Caregiver Grief Inventory (Short Form) [dissertation]. Coimbra: Faculdade de Psicologia e de Ciências da Educação; 2014.

43. Rebelo JE. Defilhar: como viver a perda de um filho. Alfragide: Casa das Letras; 2013. ISBN 9789724621524

44. Butler AE, Hall $H$, Copnell B. The changing nature of relationships between parents and healthcare providers when a child dies in the paediatric intensive care unit. J Adv Nurs. 2018;74(1):89-99.

45. Miyaji NT. The power of compassion: truth-telling among American doctors in the care of dying patients. Soc Sci Med. 1993;36(3):249-64.

46. Cardoso RM. Competências clínicas de comunicação. Porto: Afrontamento; 2019. ISBN 9789899795303

47. Dyregrov K, Dyregrov A. Effective grief and bereavement support: the role of family, friends, colleagues, schools and support professionals. London: Jessica Kingsley Publishers; 2008. ISBN 9781843106678

48. Colimão MC. Espiritualidade em cuidados paliativos: estados espirituais da família após a perda de um ente querido - perspectivas para o serviço social [dissertation]. Lisboa: Faculdade de Medicina da Universidade de Lisboa; 2014.

49. Becker G, Xander CJ, Blum HE, Lutterbach J, Momm F, Gysels M, et al. Do religious or spiritual beliefs influence bereavement? A systematic review. Palliat Med. 2007;21(3):207-17.

50. Hocking MC, Kazak AE, Schneider S, Barkman D, Barakat LP, Deatrick JA. Parent perspectives on family-based psychosocial interventions in pediatric cancer: a mixed-methods approach. Support Care Cancer. 2014;22(5):1287-94.

51. Centro Hospitalar Universitário de São João. Oncologia pediátrica do Norte [homepage]. Porto: CHUS]; 2019. Available from: https://portalchsj.min-saude.pt/pages/635

52. Black D. The dying child. BMJ. 1998;316(7141):1376-8.

53. Bergstraesser E. Pediatric palliative care: when quality of life becomes the main focus of treatment. Eur J Pediatr. 2013;172(2):139-50.

54. Acreditar - Associação de Pais e Amigos de Crianças com Cancro. Sobre a Acreditar [homepage]. Lisboa: Acreditar.org.pt; 2020. Available from: https://www.acreditar.org.pt/pt/base1/1

55. Kaba R, Sooriakumaran P. The evolution of the doctor-patient relationship. Int J Surg. 2007;5(1):57-65.

56. Snaman JM, Kaye EC, Levine DR, Cochran B, Wilcox R, Sparrow CK, et al. Empowering bereaved parents through the development of a comprehensive bereavement program.J Pain Symptom Manage. 2017;53(4): 767-75.

57. Delgado-Rodríguez M, Llorca J. Bias. J Epidemiol Community Health. 2004;58(8):635-41.

58. Frey LR, Botan $\mathrm{CH}$, Kreps $\mathrm{GL}$. Investigating communication: an introduction to research methods. 2nd ed. Boston: Pearson; 1999. ISBN 9780205198269

59. Baker SE, Edwards R. How many qualitative interviews is enough? Expert voices and early career reflections on sampling and cases in qualitative research [Internet]. National Center for Research Methods; 2012. Available from: http://eprints.ncrm.ac.uk/2273/4/how_many_interviews.pdf

60. Centro Hospitalar Universitário de São João. Carta de humanização [homepage]. Porto; CHUSJ; 2009. Available from: https://portal-chsj.minsaude.pt/pages/23

\section{CONFLITO DE INTERESSES}

Os autores declaram não possuir quaisquer conflitos de interesse.

\section{ENDEREÇO PARA CORRESPONDÊNCIA}

Ana Rita Costa

E-mail: anaritaaacosta@gmail.com

https://orcid.org/0000-0002-6737-4192

Recebido em 08-05-2020

Aceite para publicação em 07-07-2021 


\section{ABSTRACT}

\section{TO LOSE A CHILD OF PEDIATRIC AGE: A QUALITATIVE STUDY OF PARENTAL BEREAVEMENT SUPPORT}

Aims: The loss of a child of pediatric age is one of the most painful experiences the human being can endure and parental bereavement is an intense and dynamic process that needs monitoring and support. Thus, we aim to identify the needs to be met in the support provided by health professionals and the Centro Hospitalar Universitário de São João (CHUSJ) to parents that experienced the loss of a child of pediatric age due to an oncologic disease and outline recommendations to improve that support.

Methods: Qualitative study based on semi-structured interviews with parents who lost a child of pediatric age due to an oncologic disease, followed at the Pediatric Oncology Service (SOP) of CHUSJ. After transcription of the interviews, the data were analyzed qualitatively using the software ATLAS.ti.

Results: Collected data confirm the recognized impact that an oncologic disease and the loss of a child has on a parent's personal, family, social and professional life. Strengths were identified in the support provided at an emotional, instrumental, and informational level, especially throughout the period of illness and at the end of life (anticipatory grief). The main aspects to be improved by the team of health professionals and the hospital relate to the communication of bad news, articulation with other health units (e.g., primary health care) or social services, and the provision of psychological support. The need to reinforce bereavement support after the child's death stands out.

Conclusion: As is done in several countries, it is pertinent to invest in pediatric palliative care and in the structuration of formal parental bereavement support programs. That being said, we consider it important to study this reality more deeply at a national level in order to better establish the points to be reinforced in the support provided to those who lose a child.

Keywords: Pediatrics; Medical oncology; Bereavement; Social support; Parents. 